\title{
OCUPAÇÕES URBANAS E DIREITOS HUMANOS À ÁGUA E SANEAMENTO: O CASO DA OCUPAÇÃO BELA VISTA - PASSO FUNDO (RS)
}

\author{
Informal Urban Settlements and human rights to water and sanitation: the case of Bela Vista \\ Occupation - Passo Fundo (RS)
}

\author{
Rafaela Cacenote ${ }^{(1)}$ \\ Bacharel em Direito pela Faculdade Anhanguera de Passo Fundo (Faplan/Anhanguera). Advogada, integra a Rede \\ Nacional de Advogadas e Advogados Populares (RENAP) e a Comissão de Direitos Humanos de Passo Fundo \\ (CDHPF).
}

\begin{abstract}
Bruna A. Branchi ${ }^{(2)}$
Docente na PUC-Campinas, Centro de Economia e Administração e Programa de Pós-graduação em Sustentabilidade. Doutora em Economia Política pela Universitá degli Studi di Pavia (Itália). Mestre em Economia pela University of Wisconsin-Madison (EUA).
\end{abstract}

E-mail ${ }^{(1)}$ : rafaela.cacenote@hotmail.com

\section{RESUMO}

A ocupação mercantil do espaço urbano expulsa parte da população para ocupações precárias, negando-lhe o direito à moradia e à vida saudável. Nelas, a ausência do título de propriedade do imóvel, restrições ambientais e renda insuficiente são apontadas como obstáculos à universalização dos serviços públicos. Através de uma revisão da literatura, algumas experiências mostram que entre o direito à propriedade privada e os direitos humanos à água e ao saneamento, estes últimos podem se concretizar e prevalecer por meio da atuação do Poder Público. Entre os exemplos de superar com sucesso os obstáculos à universalização da água e do saneamento em assentamentos irregulares, o estudo de caso escolhido oferece uma solução alternativa. O estudo da Ocupação Bela Vista em Passo Fundo mostrou que, diante de uma política municipal excludente, somente a atuação judicial da Defensoria Pública conseguiu garantir um acesso limitado à água.

\begin{abstract}
Urban development leads to a scattered urban space occupation, dropping part of the population in shantytowns, denying it the right to housing and healthy living. In them, the absence of property rights, environmental restrictions, and insufficient income are obstacles to the universalization of public services. Through a literature review, some experiences show that between the fundamental right to private property and the human rights to water and sanitation, the latter may prevail and be achieved through the action of public authorities. Among the examples of successfully dealing against obstacles to the universalization of water and sanitation in irregular settlements, the case study chosen offers an alternative solution. Given the unfair municipal policy, the study of the Bela Vista Occupation in Passo Fundo (RS) showed that only the judicial action of the Public Defender's Office was able to guarantee limited access to water.
\end{abstract}

Palavras-chave: Direitos humanos. Água. Assentamento informal. Serviços públicos.

Key words: Human rights. Water. Informal settlements. Public services.

\section{INTRODUÇÃO}

A cidade é um ambiente construído caracterizado pela presença de espaços diferenciados, com funções distintas e habitados por classes sociais diferentes. O território urbano tem um valor de uso que reflete a sua capacidade de atender às demandas sociais de moradia, trabalho, deslocamento. $\mathrm{O}$ mercado imobiliário atribui a este espaço um valor de troca que reflete sua localização, características físicas (facilidade de acesso) e a disponibilidade da infraestrutura (FURIGO, 2020). 
A mercantilização da terra urbana impacta diretamente no direito à moradia. A organização do espaço da cidade na lógica de mercado justifica a existência de terrenos urbanos mantidos vazios na expectativa de uma valorização. Ao mesmo tempo em que parte da população vê negado o direito à moradia pela impossibilidade de pagar o preço do imóvel ou do aluguel e busca soluções precárias em imóveis vazios e ocupações. Estimativa recente dos aglomerados subnormais no Brasil, calculada pelo IBGE, identificou 13.151 ocupações irregulares, abrigando mais de 5 milhões de domicílios, ou 7,8\% do total nacional. O número de aglomerados subnormais mais do que duplicou entre 2010 e 2019, distribuídos entre 734 municípios, contra os 323 de 2010 (IBGE, 2020).

Discutir a universalização dos serviços de abastecimento de água e esgotamento sanitário nas áreas irregulares das cidades brasileiras significa reconhecer os desafios resultantes do conflito de direitos: direito de propriedade privada versus direitos humanos à água e saneamento (DHAS). Há estados e municípios brasileiros em que as prestadoras atendem os residentes destas áreas irregulares somente se houver uma autorização da justiça. Mesmo nesses casos, há exemplos de arranjos específicos, ainda que transitórios, que possibilitam a disponibilização dos serviços essenciais independentemente da regularização fundiária (GUIMARÃES, 2015). A negação dos DHAS, por outro lado, importa em prejuízos ao bem-estar, à saúde, qualidade de vida e pertencimento das populações de ocupações urbanas, o que impõe uma obrigação urgente ao Poder Público para garantir a universalização desses direitos, dispondo de instrumentos para tanto.

Neste artigo discute-se o tema da implementação dos DHAS em ocupações irregulares a partir de revisão de literatura e de estudo de caso, a Ocupação Bela Vista em Passo Fundo/RS, visando identificar possíveis soluções, mesmo temporárias, que podem ser adotadas para promover o acesso universal à água e ao esgotamento sanitário em assentamentos urbanos informais.

\section{METODOLOGIA}

Trata-se de uma pesquisa exploratória e descritiva, com abordagem qualitativa. Através da revisão de literatura são selecionadas algumas experiências de abastecimento de água e esgotamento sanitário em aglomerado subnormais que visam promover a universalização dos serviços. $\mathrm{O}$ estudo de caso, relativo à Ocupação Bela Vista em Passo Fundo (RS), oferece a oportunidade de investigar a possível efetivação do serviço público de abastecimento de água nesses locais, ante a sistemática negativa de acesso aos DHAS pelo Poder Público, o qual foi realizado nos meses de julho e agosto de 2021, a partir da observação e coleta de informações in loco junto às lideranças e moradores da ocupação, no intuito de identificar e compreender as carências no acesso aos serviços essenciais ao longo dos últimos anos, bem como o perfil socioeconômico de seus ocupantes.

\section{RESULTADOS E DISCUSSÃO}

\subsection{Aglomerados subnormais e direito ao saneamento básico}

Nas ocupações irregulares há diferentes obstáculos para a universalização dos serviços públicos: ausência de um título de propriedade, restrições ambientais, precariedade da situação econômica dos residentes. Neste estudo está sendo privilegiada a discussão relacionada à irregularidade fundiária e suas consequências para a universalização do direito.

O marco dos DHAS orienta a solução deste dilema. Bos (2017) aponta que se os DHAS estiverem na constituição haveria maior poder para concretizar a universalização desses direitos. Na sua ausência, podem ser adotadas soluções temporárias como contratos onde a oferta desses serviços é realizada sem implicar o direito de propriedade do local (BOS, 2017). Exemplos destes contratos ocorreram em Bangladesh e Marrocos. 
Em Porto Alegre, em 2005, foi iniciado o Programa Água Certa para regularizar o acesso à água e esgotamento sanitário em áreas irregulares, visando minimizar o desperdício de água e a cobrança pelo serviço. A Lei municipal 570/2007 (PORTO ALEGRE, 2007) estabelece as condições, incluindo a necessidade de apresentação do título de propriedade, contrato de compra e venda ou a posse legal da área. O projeto "Consumo Responsável" visa regularizar o acesso ao abastecimento de água e esgotamento sanitário em áreas que aguardam uma decisão judicial. O abastecimento, de natureza provisória, é realizado com tecnologias de baixo custo e com medidores coletivos, garantindo $10 \mathrm{~m}^{3}$ de água por mês por economia, em 3 horários definidos por dia, ajustados de acordo com a comunidade atendida (PORTO ALEGRE, 2016). Em contrapartida os usuários se comprometem a pagar pelo serviço, com a possibilidade de suspensão em caso de inadimplência. Há envolvimento das lideranças dos assentamentos e o estímulo da participação social.

No município de Piracicaba (SP), a partir da década de 1990, implementou-se uma política municipal para atender os residentes em aglomerados subnormais. Se a área não for sujeita a restrições ambientais, inicia-se a urbanização e somente em um segundo momento ocorre o processo de regularização fundiária. É previsto também um programa de subsídios para os moradores com contas atrasadas, através do qual a Secretária Municipal de Desenvolvimento Social quita, uma única vez, a dívida para evitar a interrupção do serviço (YOSHII, 2017).

No Rio Grande do Sul, em 2017, a Companhia Riograndense de Saneamento (CORSAN) iniciou o programa “Água, Vida e Cidadania” de regularização de ligações clandestinas de água, por meio de parcerias firmadas com municípios, objetivando atender assentamentos urbanos precários consolidados, com mais de cinco anos e que tenham ligações irregulares de água. A primeira ligação é gratuita, são concedidos três meses de suspensão do faturamento, há trabalho de conscientização sobre o consumo, além de tarifa social aplicada por dois anos. O programa atendeu 1.635 imóveis no Rio Grande do Sul, beneficiando 4.905 pessoas. A meta é atingir 10.631 ligações até o final de 2022, beneficiando aproximadamente 35 mil pessoas (CORSAN, 2021).

Os exemplos apresentados mostram que para promover o acesso universal aos serviços de água e esgotamento sanitário devem ser primeiramente superados os impedimentos legais nos assentamentos urbanos irregulares, através de arranjos político-institucionais específicos, tais como acordos entre o Poder Executivo e as prestadoras do serviço público. "Há necessidade de intervenções e articulações junto ao poder público propiciando arranjos jurídicos ainda que transitórios que permitam disponibilizar o acesso aos serviços até a regularização adequada dessas áreas ou outra solução que prestigie a dignidade humana" (GUIMARÃES, 2015, p. 299).

\subsection{Caracterização da cidade de Passo Fundo e da Ocupação Bela Vista}

Localizada na região norte do Rio Grande do Sul, distante 289 quilômetros da capital Porto Alegre, Passo Fundo é uma cidade de 204 mil habitantes que convive com numerosos litígios coletivos na área urbana. A cidade tinha em 2017 mais de 50 ocupações (WEISSHEIMER, 2017). Em 2019 eram 72 ocupações em áreas públicas e privadas (PALUDO, 2019). O elevado número de conflitos fundiários está atrelado à ausência de formulação de políticas públicas habitacionais voltadas à população mais vulnerável, a fim de concretizar o direito constitucional à moradia, a função social da propriedade, a realização de justiça social e democratização da cidade. Não são utilizados mecanismos de política urbana para conter a especulação imobiliária, o que resulta em grandes vazios urbanos, tal como na área ocupada pelos moradores da Ocupação Bela Vista desde 2015.

O Poder Público municipal, na concretização das normas urbanísticas e diretrizes de ocupação do solo não distribui de maneira igualitária os benefícios e encargos do processo de desenvolvimento da cidade, não estimula o acesso à propriedade e habitação pela população mais vulnerável, não leva em conta o bem-estar dessa população. Essas diretrizes são formuladas sem levar em conta a 
função econômico-social da cidade e a efetiva participação popular, contribuindo para agravamento da desigualdade social, estimulando a especulação imobiliária e o crescente número de ocupações na última década. Tudo isso viola os objetivos elencados no art. $5^{\circ}$, do Plano Diretor de Desenvolvimento Integrado de Passo Fundo (Lei Complementar $n^{\circ} 170$, de 2006), as suas premissas e princípios, tais como a função social da propriedade (art. $4^{\circ}$, I, do PDDI) e a supremacia do interesse público sobre o interesse individual (art. $3^{\circ}$, II, do PDDI), que tem estatura constitucional.

A Ocupação Bela Vista é formada por aproximadamente 200 famílias que ocupam uma gleba de cerca de 6 hectares, desde maio de 2015, não urbanizada, que não tinha destinação imediata à época. Era um grande vazio urbano, próximo ao Centro, que não cumpria a sua função social. Localiza-se na região leste de Passo Fundo, entre os Bairros Petrópolis e São Luiz Gonzaga, às margens da Rua Princesa Isabel, importante via que liga os dois bairros à Avenida Brasil, principal via municipal. Na outra margem da Rua Princesa Isabel está localizada a Ocupação Vista Alegre e o condomínio Parque Princesa Isabel - são 8 torres de 10 pavimentos, totalizando 640 unidades de dois dormitórios e área total de $43 \mathrm{~m}^{2}$ —, viabilizado a partir de uma flexibilização do PDDI. Tratase de empreendimento dos mesmos proprietários da área da Ocupação Bela Vista. Inicialmente classificada como Zona de Proteção dos Recursos Hídricos (ZPRH), por estar localizada às margens do rio que dá nome ao município, a área foi reclassificada como Zona Especial de Interesse Social (ZEIS 1), destinada a habitação e parcelamento de interesse social.

A área da ocupação é objeto de três ações judiciais de reintegração de posse, autuadas em conjunto perante a $4^{\mathrm{a}}$ Vara Cível de Passo Fundo. A ordem de reintegração de posse da área encontra-se suspensa, havendo recente decisão do juízo, em 2021, pela inviabilidade do cumprimento da medida, pelo longo período transcorrido desde o ajuizamento das ações, aliado ao expressivo número de famílias que ali residem e à pandemia da Covid-19. Há tratativas do Poder Público municipal para realocar as famílias em uma área rural localizada no Bairro Jaboticabal, na região oeste, distante 10 quilômetros da Ocupação Bela Vista, que seria transformada em área urbana.

A área da ocupação foi dividida em 150 lotes, medindo de $8 \mathrm{~m}$ x $20 \mathrm{~m}$ a $20 \mathrm{~m}$ x 30m. Os moradores abriram as vias internas com dimensões semelhantes àquelas previstas no plano diretor, de 9 a 12 metros de largura. Não há pavimentação e passeio público, o que dificulta a acessibilidade. Alguns postes foram instalados pelos moradores e garantem a iluminação das vias no período noturno. Não há recolhimento do lixo doméstico na área interna da ocupação, de modo que alguns moradores optam por queimá-lo, contribuindo para a degradação da qualidade do ar.

As residências em sua maioria são de madeira, sem acabamento, com instalações elétricas, hidráulicas e sanitárias precárias. Algumas são mistas, espaçosas e bem acabadas. Quanto ao saneamento, algumas moradias contam com banheiro interno, outras com banheiro externo e há relatos de pessoas que fazem suas necessidades ao ar livre. Não há sistema de coleta e tratamento de esgoto, embora as residências tenham fossas rudimentares, individuais ou coletivas (MOREIRA, 2018). Muitas estão sobrecarregadas por não passarem por limpeza periódica e manutenção, verificado in loco em julho e agosto de 2021, o que faz com que o esgoto corra a céu aberto, impactando negativamente as residências localizadas nas áreas mais baixas e o Rio Passo Fundo.

Não há fornecimento regular de energia elétrica pela RGE Sul Distribuidora de Energia S.A., concessionária do serviço público. As ligações clandestinas são realizadas a partir de poste localizado na Rua Princesa Isabel e há registro de incêndios em casas da ocupação nesses 6 anos.

Quanto ao perfil demográfico predominante, $88 \%$ dos moradores ingressaram na Ocupação Bela Vista em razão da falta de moradia e a maioria já residia em Passo Fundo (86\%). Quanto à idade, $36 \%$ têm entre 19 e 29 anos. 62\% dos chefes de família são mulheres, sendo que $78 \%$ dos moradores têm 3 filhos. Quanto ao grau de instrução e renda, 58\% não tinham completado o ensino fundamental, $82 \%$ recebiam até 1 salário-mínimo, 50\% recebiam meio salário-mínimo e 33\% 
complementavam a renda com programas sociais. Quanto à ocupação atual, 25\% exerciam atividade informal, enquanto 36\% não exercia atividade remunerada (MOREIRA, 2018).

A água é fornecida pela CORSAN através de bicas públicas. Três bicas públicas de água, custeadas pelo município, foram instaladas na ocupação em abril de 2020, por decisão do Tribunal de Justiça do Rio Grande do Sul, proferida em recurso apresentado na Ação Civil Pública movida pela Defensoria Pública contra o município e a CORSAN, tendo como objeto o fornecimento de água potável a mais de 630 famílias que residem em ocupações urbanas em Passo Fundo/RS, incluindo a Bela Vista, no contexto da pandemia. Atualmente as ligações de água localizadas na Ocupação Bela Vista são feitas com mangueiras, precárias, improvisadas e não atendem às condições mínimas de segurança, havendo risco de contaminação. A pressão da água é baixa em alguns pontos e algumas casas acessam o bem de forma intermitente, dificultando higiene pessoal, lavagem de roupas, limpeza das residências e preparo de alimentos. Nem todas as casas possuem caixas d'água.

A criação do condomínio Parque Princesa Isabel contribui para o despejo dos moradores da Ocupação Bela Vista, em um processo de segregação alimentado pelas dinâmicas imobiliárias verificadas no Bairro São Luiz Gonzaga. Também gera prejuízo ao município, porque impõe aumento abrupto e bastante significativo na densidade populacional e construtiva, em área antes identificada como vazio urbano, trazendo reflexos importantes ao sistema viário, que ficará sobrecarregado. Também há impacto negativo na paisagem urbana pela verticalidade do empreendimento, que destoa do padrão de moradia verificado na região (GALLINA, 2019).

\section{CONCLUSÃO}

A universalização do acesso à água e saneamento básico em ocupações urbanas em muitos casos encontra obstáculos que se justificam na ausência de título de propriedade do imóvel, restrições ambientais e renda insuficiente de seus residentes. Em alguns estados e municípios brasileiros a implementação dos DHAS somente ocorre por meio de arranjos institucionais específicos entre o Poder Público e as concessionárias do serviço público ou por atuação do Poder Judiciário. O caso da Ocupação Bela Vista é um exemplo da implementação dos DHAS, ainda que de forma temporária, via Ação Civil Pública movida pela Defensoria Pública, no contexto da pandemia e em razão da omissão do ente público municipal. O estudo de caso possibilitou observar a efetivação do serviço público de abastecimento de água em uma ocupação urbana localizada no Município de Passo Fundo/RS, ante a sistemática negativa de acesso aos DHAS pelo Poder Público municipal. Também possibilitou acompanhar a evolução da Ocupação Bela Vista desde 2018, ano em que outra pesquisa buscou identificar a área, o perfil socioeconômico de seus moradores e o padrão das residências. O presente estudo de caso, realizado entre julho e agosto de 2021, apresentou limitações em razão do tempo e do contexto da pandemia, contudo foram coletadas informações junto aos moradores e lideranças da ocupação, identificando-se importantes carências no acesso aos DHAS e outros serviços essenciais, uma vez que a rede de distribuição de água ainda é improvisada e houve o agravamento das condições no que concerne ao esgotamento sanitário. A aplicação de questionários e entrevistas mais detalhadas com os moradores da Ocupação Bela Vista possibilitaria a identificação das perdas e os danos socioeconômicos e ambientais impostos aos ocupantes, causados pela negação ao acesso aos DHAS decorrente da atuação omissa do Poder Público local.

\section{REFERÊNCIAS}

BOS, R. Manual sobre os Direitos Humanos à Água Potável e Saneamento para profissionais. Londres, IWA, 2017. 
CORSAN - Companhia Riograndense de Saneamento. Programa Água, Vida e Cidadania. Rio Grande do Sul, maio de 2021. Disponível em: https://www.corsan.com.br/programa-agua-vida-ecidadania-investe-r-1-milhao-em-cachoeirinha

FURIGO, R. F. R. Universalização do saneamento no contexto dos assentamentos precários urbanos brasileiros. Tese (Doutorado em Urbanismo) - Programa de Pós-Graduação em Urbanismo, Centro de Ciências Exatas, Ambientais e de Tecnologia, Pontifícia Universidade Católica de Campinas, Campinas, 2020.

GALLINA, B. Legislação Urbanística e Materialidade: Estudo da relação entre densidade e mobilidade em Passo Fundo/RS. Dissertação (Mestrado em Planejamento Urbano e Regional) Programa de Pós-Graduação em Planejamento Urbano e Regional da Faculdade de Arquitetura na Universidade Federal do Rio Grande do Sul, 2019.

GUIMARÃES, E. F. Modelo inclusivo para a universalização do saneamento básico em áreas de vulnerabilidade social. Tese (Doutorado em Ciências da Engenharia Ambiental) - Programa de PósGraduação em Ciências da Engenharia Ambiental - PPGSEA, Universidade de São Paulo, Escola de Engenharia de São Carlos - EESC/ USP, 2015.

IBGE - Instituto Brasileiro de Geografia e Estatística. Aglomerados Subnormais 2019:

Classificação preliminar e informações de saúde para o enfrentamento à COVID-19. Rio de Janeiro, maio de 2020.

MOREIRA, D. A. Ocupações Urbanas em cidades de Médio Porte. Dissertação (Mestrado em Projetos de Arquitetura e Urbanismo) - Programa de Pós-Graduação em Arquitetura e Urbanismo, Faculdade Meridional, Passo Fundo, 2018.

PALUDO, L. Moradia e meio ambiente na mesma equação. O Nacional, 29 de junho de 2019. Disponível em: https://www.onacional.com.br/cidade,2/2019/06/29/moradia-e-meio-ambiente-na$\underline{\text { mesma, } 91702}$

PORTO ALEGRE. Programa Consumo Responsável. 2016. Disponível em: https://www2.portoalegre.rs.gov.br/dmae/default.php?p_secao=26

PORTO ALEGRE. Lei Complementar $\mathrm{n}^{\circ}$ 570, de 11 de junho de 2007. Estabelece condições para a instalação de redes de abastecimento de água e de remoção de esgoto cloacal em áreas nãoregularizadas e dá outras providências. Diário Oficial de Porto Alegre em 13/06/2007.

ROLNIK, R. O que é a cidade. 6ª reimpressão (2009). São Paulo: Brasiliense, 1995.

WEISSHEIMER, M. Com mais de 50 ocupações, Passo Fundo vive um dos maiores conflitos fundiários urbanos do RS. Sul21, 2 de julho de 2017. Disponível em:

https://sul21.com.br/cidadesz_areazero/2017/07/com-mais-de-50-ocupacoes-passo-fundo-vive-umdos-maiores-conflitos-fundiarios-urbanos-do-rs/

YOSHII, M. P. C. Práticas que promovem o acesso aos serviços de abastecimento de água e esgotamento sanitário em aglomerados subnormais no município de Piracicaba - SP. Dissertação (Mestrado em Ciências da Engenharia Ambiental) - Programa de Pós-Graduação em Ciências da Engenharia Ambiental - PPGSEA, Universidade de São Paulo, Escola de Engenharia de São Carlos - EESC/ USP, 2017. 